\title{
Human Resources Cost Control Model of New Enterprise in Concept of Intelligent Logistics Backbone Network
}

\author{
LI Yao-hua ${ }^{1, a}$ \\ ${ }^{1}$ Su Zhou Vocational University, Suzhou Jiangsu, 215104 \\ aliyaohualyh@163.com
}

\begin{abstract}
Keywords: intelligent logistics backbone; human resource; new enterprises; control model; intelligent logistics
\end{abstract}

\begin{abstract}
The Internet has promoted rapid development of new enterprise, the new logistic business has taken great development, the human resource cost accounting method cannot meet the development of logistic development, and the human cost accounting method cannot reasonably amortize the initial investment and other issues, the human resource cost accounting and control model should be developed. An improved human resources cost control model of new enterprise is proposed in concept of intelligent logistics backbone network, the intelligent logistics backbone network is constructed, and the sales growth model is taken as the basis, and the application of new enterprises human cost accounting amortization model is researched. The simulation is taken combined with the practical example, the defect of traditional enterprise human cost control model is solved, the human resource control and accounting model is constructed, it can be used by the emerging enterprises, the human resource control problem can be solved, and it provides theoretical basis for the rapid development of emerging enterprises. This new model will have good application value in practice.
\end{abstract}

\section{Introduction}

With the rapid development of domestic economy of China, it provides a great opportunity to the development of logistics industry. The electronic commerce is taken as the example, the online trading activity is frequent, and the electronic commerce and online trading are becoming as an important and main trading mode for the people, this trading model has taken a great development of logistics industry, and the logistics business is combined with the electronic commerce. Many logistics business is shown as saturation, and the human resources is scarce, how to manage the human resource is becoming as a great subject of the logistic business, how to overcome the phenomenon of "the slowest expressage" is becoming an important problem should be solved. Therefore, the development of electronic commerce results in the development of huge logistics business, the requirements of speed and real time of logistic business is the basement of the industry. The more large-scale logistics company is needed, and the good efficient logistics system is necessary. The emergence of intelligent logistics backbone network can meet the requirement of development needs of the modern logistics. Compared with the backbone network intelligent logistics of developed countries, the backbone network intelligent logistics of China is lack of mature experience, and it should be modified with the practice of the modification.

In this paper, an improved human resources cost control model of new enterprise is proposed in concept of intelligent logistics backbone network, the intelligent logistics backbone network is constructed, and the sales growth model is taken as the basis, and the application of new enterprises human cost accounting amortization model is researched. The simulation is taken combined with the practical example, the defect of traditional enterprise human cost control model is solved, the human resource control and accounting model is constructed, it can be used by the emerging enterprises, the human resource control problem can be solved, and it provides theoretical basis for the rapid development of emerging enterprises. This new model will have good application value in the practice of logistics management of human resource control. 


\section{Model construction of human resource costing and control in intelligent logistics backbone network}

In this paper, the unit output method and the total income method are taken for constructing the human resources cost control model of new enterprise in concept of intelligent logistics backbone network, the logistics model is expressed as $S=P \times Q W$. In the concept of intelligent logistics backbone network, assumed the human resources cost amortization expenses is TC, the final no amortization human cost is shown as WC, the initial backbone network development quantity is $\mathrm{QW}$, the current development quantity of the backbone network is $\mathrm{N}$, so we can calculate TC as:

$$
T C=\frac{W C}{Q W} \times N
$$

In practical application process, the unit output method calculation formula can be expressed as:

$$
T C=\frac{W C}{Q W+N} \times N
$$

From the formula (1) and the formula (2), we can conclude that the denominator is the total investment in the development of intelligent logistics network backbone, and the molecule is the enterprise human capital investment cost, the enterprise human capital investment cost and the total investment quality in the intelligent logistics backbone network is same, it is similar to principle of human cost amortization. At the same time, the amortization of human cost and intelligent logistics backbone network is inversely proportional to the amount of investment direction, and the human capital investment cost of current enterprise is shown in the same direction. With the amount and the enterprise human capital investment change, the human resource cost is changing synchronously. Furthermore, the development intelligent logistics investment amortization of human cost can be calculated, and the human resource s cost of every enterprise can be optimized, the revenue of the enterprise of year is matched to the human cost effectively.

In the new enterprise intelligent logistics backbone network, if the development quality has obviously disproportionate to the capital investment, the unit output method is selected as the calculation method, and the amortization of human cost accounting is constructed, it will cause the investment cost of human resource and intelligent bone logistics network development of intelligent backbone enterprises, it cannot match the enterprises operating profit, now the total income method is selected as the calculation method, the total income method is used to calculate the human resources costs, the current total revenue is taken as the basis for future calculation of $\mathrm{MC}$, in the new enterprise intelligent logistics backbone network, assumed the final benefit of backbone network is MC, and benefit of backbone network is WS, the intelligent logistics has been developed for the new enterprise, the current profit of the enterprise is D, the amortization of human cost accounting formula is specifically shown as follows:

$$
T C=\frac{Q W}{W S} \times D
$$

Where

$$
\begin{aligned}
& W S=P \times Q W \\
& D=D P \times D N
\end{aligned}
$$

In the formula, $\mathrm{P}$ is the no present income of new enterprise, $\mathrm{QW}$ is the development quality of intelligent logistics backbone network, DP is the current present income of new enterprise, DN is the current development quality of new enterprise backbone network of intelligent logistics. The formula (4) and the formula (5) are taken into the formula (3), we can get that:

$$
T C=\frac{Q W}{P \times Q W} \times(D P \times D N)
$$

According to the fully human cost amortization method, the development quality of new enterprise intelligent logistics backbone network is the base of amortization cost center, and the new enterprises need to amortize capitalized cost, the network development of the relative amount is 
matched to the capitalized cost. The new enterprises need to amortize capitalized cost, in the new enterprise accounting intelligent logistics network process, if it does not match the situation, the calculation of the new enterprise amortization manpower cost needs to adjust the amortized investment cost. The enterprise amortization includes the intelligent logistics backbone network management and cost control part, it has developed the unexplored parts, the developed part is put in the application, and the unexplored part should be invested additionally. Therefore, the new enterprise amortization intelligent logistics backbone network contains the investment of unexplored intelligent logistics backbone network. In the cost accounting process of investment, the new enterprise should take the human cost amortization into consideration, the human resource consumption is YT, the calculation formula is shown as:

$\mathrm{YT}=$ Cost of enterprise investment - Accumulated amortization investment + Future development costs

It is shown as:

$Y T=T Z-T^{\prime}+W K$

Where, TZ is the intelligent logistics network investment cost of new enterprise investment, TC' is accumulated amortization human cost of new enterprise, WK is future development human cost.

Combined with the discussion and research of intelligent logistics network human cost control model, the human cost amortization model of the new enterprise intelligent logistics backbone network can be expressed as:

$$
T C^{*}=T C+Y T=\left[\frac{Q W}{P \times Q W} \times(D P \times D N)\right]+\left(T Z-\mathrm{TC}^{\prime}+\mathrm{WK}\right)
$$

\section{Example and experiment}

In order to test the performance of the new model, the experiment is taken based on the real samples, the intelligent logistics backbone network is constructed, and the investment human cost is 1000000 Yuan. The cost of construction of intelligent logistics network is 15000000 Yuan. Before the construction of intelligent key logistics network, the new company has two logistics network, the cost of logistics network is 2000000 Yuan, it is expected to develop ten intelligent logistics backbone networks with the same cost. In 2010, the intelligent logistics backbone network revenue was 200000 Yuan, including 55000000 Yuan is the budget out of income, and 5000000 Yuan is the development benefits, according to formula model, the enterprise amortization cost is calculated, and it is shown as below:

The development of intelligent logistics backbone network of new enterprise for human cost is W:

$\mathrm{W}=(55000000 \div 600000000) \times 15000000=13750000$ Yuan

In the intelligent logistics backbone network, the new enterprise needs to be amortized human resource cost is $\mathrm{C}$ :

$$
\begin{aligned}
C & =(55000000 \div 600000000) \times 10000000 \\
& =1000000+2000000 \times 2+\left(\begin{array}{l}
150000000- \\
13750000
\end{array}\right)-5000000 \quad \text { Yuan }=5750000 \text { Yuan }
\end{aligned}
$$

In the intelligent logistics backbone network, the amortization of human resources is T:

$$
T=[5750000 \div(5000000+400000)] \times 400000=425926 \text { Yuan }
$$

According to the traditional human cost amortization method, the amortization of manpower cost of intelligent logistics backbone network is calculated as:

The human cost of intelligent logistics backbone network is $\mathrm{H}$ :

$$
H=(10 \div 12) \times 15000000=12500000
$$

In the intelligent logistics backbone network, the human resource cost of new enterprise needs to be controlled is $\mathrm{Yu}$ : 
$Y u=1000000+2000000 \times 2+\left(\begin{array}{l}150000000- \\ 12500000\end{array}\right)-5000000=7000000$ Yuan

The manpower cost of new enterprise intelligent logistics backbone for amortization can be calculated as:

$$
H t=[7000000 \div(5000000+400000)] \times 400000=518519 \text { Yuan }
$$

Through the calculation results, we can see that the new model can save the cost greatly, the calculation results of human resource cost of new model is 425926 Yuan, it is far less than the traditional cost 518519 Yuan, the new model has a certain practical significance and general applicability.

\section{Conclusion}

According to the traditional human resource control model of intelligent logistics backbone network, the human resource cost accounting method cannot meet the development of logistic development, and the human cost accounting method cannot reasonably amortize the initial investment and other issues, the human resource cost accounting and control model should be developed. An improved human resources cost control model of new enterprise is proposed in concept of intelligent logistics backbone network, the intelligent logistics backbone network is constructed, and the sales growth model is taken as the basis, and the application of new enterprises human cost accounting amortization model is researched. The simulation is taken combined with the practical example, the defect of traditional enterprise human cost control model is solved, the human resource control and accounting model is constructed, it can be used by the emerging enterprises, the human resource control problem can be solved, and it provides theoretical basis for the rapid development of emerging enterprises. According to the simulation results, we can get the new model can save the cost greatly, and the calculation result is far less than the traditional cost. This new model will have good application value in practice. It can help enterprises successfully to build a smart key logistics network.

\section{References}

[1] Song Minghong, Yu Huafeng, Chen Haiyan. Application of Improved Quantum Evolutionary Algorithm in Computer Network's Routing Choice[J]. Bulletin of Science and Technology, 2014,30(1):170-173.

[2] Liu Xiangdong. Data Clustering Algorithm and Software Design Based on Disturbance Searching of Logistic Series[J]. Bulletin of Science and Technology, 2014,30(2): 161-163.

[3] MA Jian- hong, JI Li- xia. Study on Agent Immune Network Monitoring System Model[J]. Computer Simulation, 2013, 30(5): 213-216.

[4] LIU Luo, GUO Li-Hong, XIAO Hui, Et al. Software Reliability Growth Model Based on Dynamic Fuzzy Neural Network with Parameters Dynamic Adjustment[J]. Computer Science, 2013, 40(2): 186-190.

[5] Xing Li. Study on Information Recommendation System Based on Cloud Computation[J]. Logistics Technology, 2013, 32(2): 185-188. 